\title{
Desempenho reprodutivo do beijupirá (Rachycentron canadum) capturado no litoral de Pernambuco
}

\author{
[Reproductive performance of cobia (Rachycentron canadum) captured \\ of Pernambuco, Brazil] \\ R.B. Peregrino Jr., S. Hamilton, E.C. Domingues, J.C. Manzella Jr., \\ F.H.V. Hazin, R.O. Cavalli \\ Universidade Federal Rural de Pernambuco - UFRPE - Recife, PE
}

\begin{abstract}
RESUMO
O desempenho reprodutivo de exemplares selvagens de beijupirá capturados no litoral de Pernambuco e aclimatados ao cativeiro foi avaliado durante 10 meses. Um plantel composto por duas fêmeas (peso de 14 a $16 \mathrm{~kg}$ ) e quatro machos (cerca de $12 \mathrm{~kg}$ ) mantidos em um único tanque de $70 t$ produziu 48,7 milhões de ovos no período de outubro a junho. As fêmeas foram capazes de desovar 21 vezes, com uma frequência média $( \pm D P)$ de uma desova a cada 11,9 dias $( \pm 2,9)$. Em média, cada desova produziu 2,4 milhões de ovos, com fertilização de $52,4 \%$, o que resultou em aproximadamente 1,0 milhão de larvas por desova. Os resultados demonstram a viabilidade da metodologia empregada na formação do plantel e no manejo de reprodutores e confirmam a relativa facilidade de obtenção de desovas espontâneas do beijupirá em cativeiro. Também foi confirmado que o período reprodutivo dessa espécie em cativeiro se estende além do observado na natureza. Este é o primeiro relato sobre o desempenho reprodutivo do beijupirá em cativeiro no Brasil.
\end{abstract}

Palavras-chave: aquicultura, piscicultura marinha, reprodução, desova

\begin{abstract}
The reproductive performance of wild cobia caught off the coast of Pernambuco, northeastern Brazil, was assessed. Six breeders (two females with $14-16 \mathrm{~kg}$ and four males with approximately $12 \mathrm{~kg}$ each) were maintained in a 70 ton tank from October to June and produced 48.7 million eggs. Females were able to spawn every 11.9 days ( \pm 2.9$)$, which resulted in 21 spawns. On average each spawn produced 2.4 million eggs with a fertilization of $52.4 \%$, which resulted in approximately 1.0 million larvae per spawn. The present results demonstrate the feasibility of the methodology employed here in the formation and management of a cobia breeding stock and confirm the ease of spawning cobia in captivity. It was also confirmed that the spawning season may be extended under captivity when compared to the wild stock. This is the first report on the reproductive performance of cobia in captivity in Brazil.
\end{abstract}

Keywords: Aquaculture, marine fish farming, reproduction, spawning

\section{INTRODUÇÃO}

A piscicultura marinha tem apresentado uma das maiores taxas anuais de crescimento entre os vários setores da aquicultura (FAO, 2011). No caso do Brasil, apesar das ótimas condições ambientais e da ocorrência de espécies de peixes com alto potencial, esta atividade ainda não contribui significativamente na produção de

Recebido em 5 de junho de 2012

Aceito em 7 de novembro de 2013

*Autor para correspondência (corresponding author)

E-mail: ronaldocavalli@gmail.com pescado (Brasil, 2011). Entre as espécies nativas da costa brasileira, o beijupirá (Rachycentron canadum) apresenta alta taxa de crescimento, conversão alimentar relativamente baixa, bom valor de mercado e filé de qualidade (Liao e Leaño, 2007). Em 2011, a produção mundial dessa espécie pela aquicultura foi de $40.863 \mathrm{t}$ (FAO, 2013). China, Taiwan e o Vietnã são os principais produtores, embora existam projetos de pesquisa e desenvolvimento em vários outros países. No Brasil, iniciativas de criação do 
beijupirá estão em desenvolvimento na Bahia, em Pernambuco, no Rio Grande do Norte, em São Paulo e no Rio de Janeiro (Cavalli et al., 2011).

Apesar do interesse crescente na aquicultura do beijupirá, estudos que tratem da reprodução dessa espécie em cativeiro, etapa fundamental no estabelecimento da cadeia produtiva, são inexistentes no Brasil. Em vista disso, o presente trabalho teve como objetivo avaliar o desempenho reprodutivo de um plantel de animais selvagens capturados na costa de Pernambuco e mantidos em cativeiro durante 10 meses.

\section{MATERIAL E MÉTODOS}

Exemplares de beijupirá foram capturados entre julho de 2005 e janeiro de 2008, na costa de Pernambuco, próximo à isóbata de $30 \mathrm{~m}$. A captura foi realizada com linha e anzol, usando-se como isca peixes que fazem parte da alimentação da espécie (Peregrino Jr., 2005): xira (Haemulon aurolineatum), mariquita (Holocentrus adscensionis), soia (Bothus ocellatus) e saramunete (Pseudupeneus maculatus). $\mathrm{Na}$ embarcação, os exemplares capturados foram acondicionados em tanques com $1 \mathrm{~m}^{3}$ de água constantemente renovada ou com injeção de oxigênio. No porto de Recife, os peixes foram transferidos para uma caixa de transporte com injeção de oxigênio e transportados por via rodoviária a um laboratório a $70 \mathrm{~km}$. A temperatura da água foi mantida em $24-25^{\circ} \mathrm{C}$ com a adição de gelo. Na chegada ao laboratório, os peixes foram anestesiados com óleo de cravo $\left(15-20 \mathrm{~g} . \mathrm{m}^{-3}\right)$, pesados, receberam o antibiótico oxitetraciclina $\left(0,01 \mathrm{mg} \cdot \mathrm{kg}^{-1}\right.$ de peso vivo) via intramuscular, e uma solução de iodo a $10 \%$ foi aspergida nas feridas. A identificação do sexo foi feita com uma cânula com diâmetro de $1 \mathrm{~mm}$ introduzida no orifício urogenital para coleta de material biológico e análise em microscópio óptico. Em seguida, os peixes foram marcados, reanimados e submetidos a banhos de formol (100mg. $\mathrm{L}^{-1}$ por 30min) e de água doce (máximo 5min) para a retirada de ectoparasitos. Finalmente, os peixes foram transferidos para tanques de quarentena com $50 \mathrm{~m}^{3}$ de água com salinidade 33 . Tubos de PVC de $50 \mathrm{~mm}$ instalados ao redor dos tanques promoveram a aeração e o movimento circular da água. Inicialmente foram oferecidos camarões
(Litopenaeus vannamei) vivos como alimento, mas gradualmente passaram a ser fornecidos pedaços de camarão, sardinha (Opisthonema oglinum) e lula (Loligo sp.) a uma proporção diária de $5 \%$ da biomassa.

No início de outubro, duas fêmeas, com peso entre 14 e $16 \mathrm{~kg}$ e quatro machos, com cerca de $12 \mathrm{~kg}$, foram selecionados e transferidos para um único tanque de maturação com $70 \mathrm{~m}^{3}(7 \mathrm{~m}$ de diâmetro e $1,8 \mathrm{~m}$ de altura), com duas janelas laterais, onde permaneceram durante 10 meses. Uma cobertura plástica impedia a incidência direta do sol, possibilitando o controle do fotoperíodo, que foi ajustado gradativamente para 14 horas diárias de luz. Água do mar previamente filtrada em areia e em um filtro de cartucho $(5 \mu \mathrm{m})$ era renovada a uma taxa de $200 \%$ ao dia. A temperatura foi mantida em cerca de $28^{\circ} \mathrm{C}$ com o uso de um resfriador (chiller). A temperatura da água e a concentração de oxigênio dissolvido foram monitoradas três vezes ao dia (sete, 12 e 17 horas) com termômetro e medidor de oxigênio portátil (Yellow Springs Instruments YSI 55, EUA). A concentração de amônia não ionizada $\left(\mathrm{NH}_{3}-\mathrm{N}\right)$ foi medida semanalmente com um espectrofotômetro (Hach Odyssey DR/2500, EUA). Da mesma forma que na quarentena, camarão, sardinha e lula foram ofertados uma vez por dia, no período da manhã, a uma proporção de $5 \%$ da biomassa. Semanalmente cápsulas de vitaminas e lecitina de soja, na forma de bolas com cerca de $1 \mathrm{~g}$, eram inseridas nas sardinhas fornecidas aos peixes.

Duas vezes por semana foram realizados tratamentos preventivos contra ectoparasitas com sulfato de cobre $\left(\mathrm{CuSO}_{4}\right)$ e ácido cítrico por uma hora. Durante o tratamento, a água dos tanques não era renovada, mas a intensidade da aeração era aumentada. As paredes laterais e o fundo dos tanques eram escovados uma vez por mês, quando o nível de água era reduzido para $25 \%$ do volume total e a renovação de água era aumentada para cerca de $500 \%$. Após a limpeza, o nível de água do tanque era restabelecido e a renovação diária de água retornava para $200 \%$. A concentração de $\mathrm{CuSO}_{4}$ também foi acompanhada semanalmente com o espectrofotômetro.

O comportamento dos peixes foi observado diariamente através das janelas laterais do tanque 
para se identificarem possíveis desovas e/ou comportamento que indicasse a ocorrência de ectoparasitos. Os ovos fertilizados (flutuantes) foram coletados em uma tela de $500 \mu \mathrm{m}$ acoplada à porção superior do tanque, enquanto os não fertilizados eram retirados por um dreno central no fundo do tanque. O número de ovos foi estimado por volumetria. A taxa de fertilização foi estimada pela relação entre o número de ovos fertilizados e o número de ovos totais (fertilizados e não fertilizados) de cada desova. A amostragem volumétrica de cada desova foi realizada com três amostras de $1 \mathrm{~mL}$ contadas em câmara de Sedgewick Rafter. Os ovos fertilizados foram desinfetados com formaldeído $38 \%\left(100 \mathrm{mg} . \mathrm{L}^{-1}\right)$ durante uma hora, antes da transferência para incubadoras circulares de 4.000L que contavam com aeração. A taxa de eclosão das larvas também foi avaliada por volumetria após homogeneização da água das incubadoras.

\section{RESULTADOS}

Ao longo do período experimental, a temperatura média $( \pm \mathrm{DP})$ da água foi de $28,3^{\circ} \mathrm{C}( \pm 0,7)$, com mínimos e máximos de $26,1^{\circ} \mathrm{C}$ e $30,2^{\circ} \mathrm{C}$, respectivamente. A concentração média $( \pm \mathrm{DP})$ de oxigênio dissolvido foi igual a 5,75mg. $\mathrm{L}^{-1}( \pm 0,96)$, com um mínimo de $3,7 \mathrm{mg} . \mathrm{L}^{-1}$. As concentrações de $\mathrm{NH}_{3}-\mathrm{N}$ e $\mathrm{CuSO}_{4}$ não ultrapassaram 0,14 e 0,40mg. $\mathrm{L}^{-1}$, respectivamente.

A primeira desova espontânea foi observada entre as 18h30min e 19h30min do dia 29 de outubro. O número de ovócitos dessa desova foi estimado em 1.256.753 (Tab. 1). As taxas de fertilização e eclosão foram estimadas em 91,9 e $85,3 \%$, respectivamente. A partir de janeiro, outras 20 desovas espontâneas foram observadas (Tab. 1), todas ao anoitecer. Das 21 desovas, 14 foram produzidas por uma fêmea. A frequência média $( \pm \mathrm{DP})$ de desovas, estimada como o intervalo de dias entre desovas de uma mesma fêmea, foi de 11,9 dias $( \pm 2,9)$.

Tabela 1. Data de ocorrência, fêmea desovante, número total de ovos, taxa de fertilização, total de ovos fertilizados por desova e número estimado de larvas produzidas por reprodutores selvagens de beijupirá (Rachycentron canadum) mantidos em laboratório durante 10 meses

\begin{tabular}{|c|c|c|c|c|c|c|}
\hline Desova & Data & Fêmea & Total de ovos & $\begin{array}{c}\text { Taxa de fertilização } \\
(\%)\end{array}$ & $\begin{array}{l}\text { Total de ovos } \\
\text { fertilizados }\end{array}$ & $\begin{array}{c}\text { Larvas } \\
\text { produzidas }\end{array}$ \\
\hline 1 & $29 / 10$ & A & 1.256 .753 & 91,9 & 1.154 .525 & 984.810 \\
\hline 2 & $14 / 01$ & B & 1.050 .000 & 20,0 & 210.000 & 135.030 \\
\hline 3 & $25 / 01$ & B & n.d. & n.d. & n.d. & n.d. \\
\hline 4 & $04 / 02$ & B & 2.436 .000 & 91,4 & 2.226 .000 & 1.998 .948 \\
\hline 5 & $10 / 02$ & A & 4.456 .000 & 24,6 & 1.096 .000 & 359.488 \\
\hline 6 & $13 / 02$ & B & 3.006 .000 & 65,1 & 1.956 .000 & 1.956 .000 \\
\hline 7 & $23 / 02$ & $\mathrm{~B}$ & 3.000 .000 & 66,7 & 2.000 .000 & 2.000 .000 \\
\hline 8 & $25 / 02$ & A & 2.300 .000 & 73,9 & 1.700 .000 & 2.006 .000 \\
\hline 9 & $03 / 03$ & B & 2.500 .000 & 44,0 & 1.100 .000 & 650.000 \\
\hline 10 & $07 / 03$ & A & 2.440 .000 & 65,6 & 1.600 .000 & 1.600 .000 \\
\hline 11 & $13 / 03$ & $\mathrm{~B}$ & 3.400 .000 & 29,4 & 1.000 .000 & 1.000 .000 \\
\hline 12 & $23 / 03$ & B & 3.200 .000 & 37,5 & 1.200 .000 & 1.200 .000 \\
\hline 13 & $25 / 03$ & A & 1.920 .000 & 33,3 & 640.000 & 320.000 \\
\hline 14 & $04 / 04$ & B & 3.600 .000 & 33,3 & 1.200 .000 & 670.000 \\
\hline 15 & $07 / 04$ & A & 2.400 .000 & 16,7 & 400.000 & 365.000 \\
\hline 16 & $13 / 04$ & B & 1.600 .000 & 87,5 & 1.400 .000 & 870.000 \\
\hline 17 & $23 / 04$ & B & 1.800 .000 & 55,6 & 1.000 .000 & 980.000 \\
\hline 18 & $25 / 04$ & $\mathrm{~A}$ & 2.400 .000 & 16,7 & 400.000 & 400.000 \\
\hline 19 & $05 / 05$ & $\mathrm{~B}$ & 1.640 .000 & 56,1 & 920.000 & 1.196 .000 \\
\hline 20 & $19 / 05$ & B & 1.600 .000 & 87,5 & 1.400 .000 & 1.400 .000 \\
\hline 21 & $03 / 06$ & B & 2.720 .000 & 51,5 & 1.400 .000 & 1.387 .400 \\
\hline Total & & & 48.724 .753 & & 24.002 .525 & 21.478 .676 \\
\hline $\begin{array}{l}\text { Média } \\
( \pm \text { DP })\end{array}$ & & & $\begin{array}{l}2.436 .238 \\
(849.486)\end{array}$ & $\begin{array}{c}52,4 \\
(25,6)\end{array}$ & $\begin{array}{l}1.200 .126 \\
(540.428)\end{array}$ & $\begin{array}{l}1.073 .934 \\
(615.417)\end{array}$ \\
\hline
\end{tabular}

n.d.= dados não disponíveis. 
A estimativa do total de ovos liberados foi superior a 48,7 milhões (Tab. 1). Todas as desovas apresentaram ovos fertilizados, sendo que a taxa de fertilização média ( \pm DP) foi igual a $52,4 \%( \pm 25,6)$, com variação entre $16,7 \%$ e $91,9 \%$ (Tab. 1). O número de ovos por desova variou entre 1.050.000 e 4.456.000, com média $( \pm \mathrm{DP})$ de $2.436 .238( \pm 849.486)$ ovos por desova. As taxas de eclosão apresentaram grande variação, o que provavelmente se deveu a erros na amostragem das larvas. A estimativa de larvas por desova variou de 135.030 a 2.006.000. O número total de larvas estimado para as 21 desovas foi superior a 21,4 milhões, com média $( \pm \mathrm{DP})$ estimada de $1.073 .934( \pm 615.417)$ larvas por desova.

Ao longo do período experimental, a maioria dos exemplares apresentou ectoparasitos, principalmente nas brânquias, sendo que um grande número se desprendia durante o tratamento com $\mathrm{CuSO}_{4}$. Análises microscópicas indicaram que o ectoparasito mais frequente foi Amyloodinium ocellatum. Os peixes parasitados por esse dinoflagelado eram observados se coçando repetitivamente no fundo do tanque, com a boca constantemente aberta, falta de apetite, presença de manchas brancas no corpo e, no caso de infestações mais severas, olhos opacos. Também foi observado muco na superfície da água, mas não foi constatada a formação de bolhas na superfície da água, provavelmente devido à alta renovação da água do tanque.

\section{DISCUSSÃO}

$\mathrm{Na}$ natureza, o beijupirá ocorre comumente isolado ou em pequenos grupos (Figueiredo e Menezes, 1980; Shaffer e Nakamura, 1989), o que pode, em alguns casos, dificultar a captura de um número suficiente de indivíduos para o estabelecimento de um plantel de reprodutores. Por essa razão, no caso de áreas com baixa abundância de juvenis e/ou adultos de beijupirá, alguns produtores têm optado por formar $\mathrm{o}$ plantel de reprodutores a partir de indivíduos juvenis. Na Ilha Réunion, na costa leste da África, Gaumet et al. (2007) optaram por estabelecer o plantel de reprodutores de beijupirá a partir de juvenis produzidos em laboratório importados de Taiwan. Na Bahia, Brasil, a estratégia escolhida foi a captura de juvenis selvagens, os quais são encontrados na Baía de
Todos os Santos (Lopes et al., 2001), e a criação até a fase adulta (Carvalho Filho, 2006). No caso de Pernambuco, assim como em outras regiões da costa brasileira, esse método pode ser inviável pelo desconhecimento de concentrações significativas de indivíduos jovens em locais específicos da costa. Além disso, o tempo e o custo associado à criação até que os peixes atinjam o período reprodutivo também devem ser considerados. De forma similar ao presente estudo, no sul dos EUA, a formação de plantel de reprodutores de beijupirá se baseou na captura de reprodutores selvagens (Arnold et al., 2002; Holt et al., 2007a; Weirich et al., 2007). No Vietnã, reprodutores maduros selecionados entre os peixes criados em tanques-rede no mar são transferidos para tanques em terra, onde são mantidos até a ocorrência de desovas espontâneas ou, preferencialmente, são induzidos a desovar por meio de injeções do hormônio LHRHa (Nhu et al., 2011).

Shaffer e Nakamura (1989) e Brown-Peterson et al. (2001) relatam que, na natureza, a espécie apresenta desova parcelada e sazonal, entre os meses de maio e agosto/setembro, o que corresponde ao verão no hemisfério norte. No Texas, EUA, Holt et al. (2007a) mantiveram reprodutores selvagens em cativeiro e confirmaram que as desovas no hemisfério norte ocorrem de maio a agosto. De modo similar, exemplares mantidos em tanques-rede no mar no norte do Vietnã desovam naturalmente do final de abril até julho, com um pico em maio (Nhu et al., 2011). Entretanto, no sul do Vietnã, onde a temperatura da água é mais alta, as desovas podem ser induzidas ao longo do ano, exceto durante o período de chuvas, que se estende de novembro a janeiro. No hemisfério sul, Van der Velde et al. (2010) estimaram que a desova de indivíduos selvagens na Austrália ocorre entre setembro e junho, com um pico entre outubro e dezembro. $\mathrm{Na}$ Bahia, as primeiras desovas naturais de reprodutores selvagens mantidos em cativeiro foram registradas em outubro (Carvalho Filho, 2006), o que está de acordo com Domingues et al. (2007), que, ao analisarem histologicamente exemplares capturados na costa de Pernambuco, concluíram que o período natural de desova do beijupirá seria de outubro a abril. Estes resultados, portanto, ratificam que a atividade reprodutiva desta espécie no nordeste do Brasil ocorre principalmente no verão. 
Domingues et al. (2007) sugerem que o período natural de desova do beijupirá na costa pernambucana se estende de outubro até abril. Neste estudo, porém, foram obtidas desovas até junho, o que sugere que o período reprodutivo de $R$. canadum em cativeiro pode se estender além do observado em condições naturais. Chang et al. (1999) e Gaumet et al. (2007) também relataram a ampliação do período de desova desta espécie em cativeiro. Embora as razões para este fenômeno ainda não sejam totalmente conhecidas, é provável que o fornecimento em abundância de alimentos de alta qualidade nutricional e a manutenção de condições ambientais favoráveis sejam fatores fundamentais neste processo. Kaiser e Holt (2005) relataram que adultos de beijupirá capturados no ambiente natural podem ser induzidos a desovar em cativeiro por meio da manipulação do fotoperíodo e da temperatura da água. Nesse caso, as desovas começaram a ser observadas a partir de 12-13 horas diárias de luz e temperatura de 25 a $26^{\circ} \mathrm{C}$ (Holt et al., 2007b). Essas desovas espontâneas poderão continuar por vários meses se essas condições ambientais forem mantidas. Com tal metodologia, o beijupirá desova naturalmente em cativeiro, o que tem permitido a extensão do período reprodutivo por até nove meses ao ano (Kaiser e Holt, 2005) e, eventualmente, a produção de ovos e larvas ao longo de todo o ano (Holt et al., 2007b).

Apesar de o período de desovas do beijupirá em cativeiro aparentemente ser mais prolongado do que no ambiente natural, a frequência de desovas parece não depender do histórico ou origem dos reprodutores. Neste estudo, o período médio entre desovas de uma mesma fêmea foi estimado em 11,9 dias. Ao analisarem fêmeas capturadas em três áreas do Golfo do México, EUA, BrownPeterson et al. (2001) observaram que a frequência de desovas não se diferenciou significativamente entre os exemplares das diferentes áreas, tendo variado de cinco a 12 dias. De modo similar, Van der Velde et al. (2010) estimaram que fêmeas de beijupirá na costa da Austrália desovariam, em média, a cada 7,6 dias. Já Holt et al. (2007a) relataram que fêmeas mantidas em cativeiro desovam cerca de duas vezes por mês.

Neste estudo, todas as desovas ocorreram ao anoitecer, o que também foi descrito por Holt et al. (2007a), Weirich et al. (2007) e Benetti et al. (2008) para fêmeas mantidas em cativeiro. A análise histológica de ovários de fêmeas selvagens de beijupirá capturadas à noite indicou a ocorrência de ovócitos hidratados, sugerindo que as desovas ocorrem à noite (Van der Velde et al., 2010). Por outro lado, Shaffer e Nakamura (1989) relatam a ocorrência de desovas de beijupirá em mar aberto durante o dia. Ditty e Shaw (1992) coletaram embriões em estágio avançado de desenvolvimento durante a manhã e, baseados no tempo estimado de desenvolvimento embrionário e eclosão, concluíram que as desovas teriam acontecido durante o dia. Esta aparente discrepância de informações permite supor que o beijupirá desova preferencialmente à noite, muito embora ocasionalmente as desovas também possam ocorrer durante o dia. Neste sentido, Gaumet et al. (2007) observaram que fêmeas que receberam implantes intramusculares de GhRH desovaram após 40 horas, o que usualmente ocorria ao entardecer e, ocasionalmente, durante o dia.

A observação do comportamento dos reprodutores nos tanques de maturação permite antecipar a ocorrência de desovas. Um a dois dias antes das desovas aqui observadas, as fêmeas apresentavam um comportamento agressivo, particularmente em relação aos machos, com perseguições e mordidas no corpo. No dia da desova, os reprodutores não se alimentavam e a fêmea permanecia nadando constantemente com a boca aberta. Ao final da tarde, o ventre da fêmea estava visivelmente dilatado, indicando a iminência da desova. No ato das desovas, apenas a fêmea desovante e todos os machos apresentavam comportamento reprodutivo, enquanto a outra fêmea permanecia indiferente. Arnold et al. (2002) e Holt et al. (2007a) relataram que, com a proximidade da desova, os beijupirás ficam mais ativos, sendo comum observar a formação de casais que nadam separadamente dos demais peixes. No presente estudo, também foi possível observar uma redução na atividade alimentar cerca de dois dias antes da desova, o que também foi relatado por Arnold et al. (2002) e Weirich et al. (2007). Estes autores também descrevem um aumento na intensidade da coloração das listas laterais que caracterizam essa espécie.

A fecundidade aumenta com o tamanho das fêmeas de beijupirá (Brown-Peterson et al., 
2001; Van der Velde et al., 2010), sendo que, para fêmeas selvagens na faixa de 4,2 a $28,3 \mathrm{~kg}$, cada desova teria uma média de aproximadamente 2,9 milhões de ovos (Van der Velde et al., 2010). Já Brown-Peterson et al. (2001) observaram que a fecundidade de fêmeas selvagens variou de 377 mil a 1,98 milhões de ovos por desova. Vários outros autores (Arnold et al., 2002; Weirich et al., 2005; Holt et al., 2007a) relatam que fêmeas de cativeiro com peso médio de aproximadamente $10 \mathrm{~kg}$ produzem de 1,2 a 2,3 milhões de ovos por desova. Embora este valor seja inferior ao observado neste estudo, quando uma média de 2,4 milhões de ovos foram liberados por desova, as fêmeas aqui avaliadas eram maiores (peso entre 14 e $16 \mathrm{~kg}$ ) e, portanto, com maior capacidade reprodutiva.

Um dos principais problemas enfrentados durante a quarentena e maturação do beijupirá foi a infestação por $A$. ocellatum. O ciclo de vida deste ectoparasito varia de três a cinco dias e compreende um estágio de crescimento (trofonte), que se alimenta de células epiteliais (Needham e Wootten, 1978), um cisto imóvel (tomonte) e um estágio móvel infeccioso com alto poder de disseminação (dinosporo). Ao se liberar do peixe, o trofonte sedimenta e forma o tomonte, que libera dinosporos, os quais nadam e se fixam à superfície externa dos peixes (Brown e Hovasse, 1946). Schwarz e Smith (1998) sugerem que o controle seja feito por meio de aplicações repetidas de $\mathrm{CuSO}_{4}$ e com a troca (ou filtração) da água. Neste estudo, banhos com uma solução de formaldeído (100g.L $\mathrm{L}^{-1}$ por 30 $\mathrm{min})$ e de água doce $(5 \mathrm{~min})$ foram efetivos quando aplicados tão $\operatorname{logo}$ a infestação era detectada e os peixes eram transferidos para um tanque limpo, visto que os tomontes podem permanecer aderidos no fundo e nas paredes do tanque (Abreu et al., 2005). Quando a infestação era severa, o tratamento com melhores resultados foi a utilização de $1,0 \mathrm{~g} . \mathrm{L}^{-1} \mathrm{CuSO}_{4}$ durante sete dias consecutivos, dentro do próprio tanque dos reprodutores. A partir de então, tratamentos preventivos com duas aplicações semanais de $\mathrm{CuSO}_{4}$ e ácido cítrico (ambos a $0,5 \mathrm{~g} . \mathrm{L}^{-1}$ ) foram adotados para manter a população do ectoparasito dentro de níveis que não afetassem os reprodutores.

A frequente ocorrência de desovas com alta fecundidade e taxa de fertilização média acima de $50 \%$ indicam a qualidade das desovas aqui obtidas. Em outros estudos, a taxa de fertilização de desovas naturais de reprodutores selvagens do beijupirá variou de $4 \%$ a $82 \%$ (Arnold et al., 2002; Carvalho Filho, 2006; Holt et al., 2007a; Nhu et al., 2011). Os resultados deste estudo, portanto, demonstram a viabilidade da metodologia empregada na formação do plantel e no manejo de reprodutores de beijupirá a partir de adultos selvagens. Este estudo também confirma a facilidade de obtenção de desovas espontâneas do beijupirá em cativeiro e indica que o período reprodutivo em cativeiro se estende além do observado na natureza. Em média, os reprodutores foram capazes de desovar a cada 12 dias, com uma fecundidade de 2,4 milhões de ovócitos/desova e taxa de fertilização acima de $50 \%$, o que resultou na produção de cerca de 1,0 milhão de larvas por desova. Este é o primeiro relato sobre o desempenho reprodutivo do beijupirá em cativeiro no Brasil e fornece dados preliminares, porém valiosos, para o desenvolvimento da aquicultura dessa espécie no país.

\section{AGRADECIMENTOS}

À SUDENE e ao CNPq, pelo apoio financeiro; à Aqualider Maricultura S.A., pela cessão da área experimental.

S. Hamilton, F.H.V. Hazin e R.O. Cavalli são bolsistas do CNPq; E.C. Domingues, da FACEPE.

\section{REFERÊNCIAS}

ABREU, P.C.; ROBALDO, R.B.; SAMPAIO, L.A. et al. Recurrent amyloodiniosis on broodstock of the Brazilian flounder Paralichthys orbignyanus: dinospore monitoring and prophylactic measures. $J$. World Aquac. Soc., v.36, p.42-50, 2005.

ARNOLD, C.R.; KAISER, J.F.; HOLT, G.J. Spawning of cobia Rachycentron canadum in captivity. J. World Aquac. Soc., v.33, p.205-208, 2002.

BENETTI, D.D.; ORHUN, M.R.; SARDENBERG, B. et al. Advances in hatchery and grow-out technology of cobia (Rachycentron canadum). Aquac. Res., v.39, p.701-711, 2008.

BRASIL. Boletim estatístico da Pesca e AquiculturaBrasil 2008-2009. Brasília, DF, Brasil: Ministério da Pesca e Aquicultura, 2011. 99pp.

BROWN, E.M.; HOVASSE, R. Amyloodinium ocellatum (Brown), a peridinian parasitic on marine fishes. A complementary study. Proc. Zool. Soc. London, v.116, p.33-36, 1946. 
BROWN-PETERSON, N.J.; OVERSTREET, R.M.; LOTZ, J.M. et al. Reproductive biology of cobia, Rachycentron canadum, from coastal waters of the southern United States. Fish. Bull., v.99, p.15-28, 2001.

CARVALHO FILHO, J. O êxito da primeira desova do bijupirá. Panorama da Aquicul., v.16, p.40-45, 2006.

CAVALLI, R.O.; DOMINGUES, E.C.; HAMILTON, $S$. Desenvolvimento da produção de peixes em mar aberto no Brasil: possibilidades e desafios. Rev. Bras. Zootecnia, vol.40, p.155-164, 2011.

CHANG, S.L.; HSIEH, C.S.; CHAO, Z.L. et al. Notes on artificial propagation and grow-out techniques of cobia (Rachycentron canadum). Fish World Mag., v.270, p.14-26, 1999.

DITTY, J.G.; SHAW, R.F. Larval development, distribution, and ecology of cobia Rachycentron canadum (Family Rachycentridae) in the northern Gulf of Mexico. Fish. Bull., v.90, p.668-677, 1992.

DOMINGUES, E.C.; PEREGRINO JR., R.B.; MANZELLA, J.C. et al. Biologia reprodutiva do beijupirá, Rachycentron canadum, capturado no litoral Pernambucano. In: CONGRESSO LATINOAMERICANO DE CIÊNCIAS DO MAR, 12., 2007, Florianópolis, SC. Anais... Florianópolis: Aoceano, p.536, 2007.

FAO. FISHSTAT PLUS: Universal software for fishery statistical time series. Version 2.3.2000. Fisheries Department Fishery Information, Data and Statistics Unit, FAO, Rome, Italy. 2011.

FAO. Cultured Aquatic Species Information Programme - Rachycentron canadum Disponível em: <www.fao.org/fishery/culturedspecies/Rachycentronc anadum/en>. Acessado em 21 ago. 2013.

FIGUEIREDO, J.L.; MENEZES, N.A. Manual de peixes marinhos do sudeste do Brasil. III. Teleostei (2). São Paulo: Museu de Zoologia da USP, 1980. 90p.

GAUMET, F.; BABET, M.C.; BETTES, A. et al. Advances in cobia, Rachycentron canadum, research in La Réunion Island (France): problems and perspectives. In: LIAO, I.C. e LEAÑO, E.M. Cobia Aquaculture: research, development and commercial production. Taiwan: Asian Fisheries Society, 2007. p.115-129.

HOLT, G.J.; FAULK, C.; SCHWARZ, M. A review of the larviculture of cobia Rachycentron canadum, a warmwater marine fish. Aquaculture, v.268, p.181$187,2007 \mathrm{~b}$.
HOLT, G.J.; KAISER, J.; FAULK, C. Advances in cobia research in Texas. In: LIAO, I.C. e LEAÑO, E.M. Cobia Aquaculture: research, development and commercial production. Taiwan: Asian Fisheries Society, 2007a. p.45-56.

KAISER, J.; HOLT, G.J. Species profile: cobia. Southern Regional Aquaculture Center (SRAC) Publication no. 7202. Stoneville, Mississippi, USA: SRAC, 2005. 6p.

LIAO, I.C.; LEAÑO, E.M. Cobia Aquaculture: research, development and commercial production. Taiwan: Asian Fisheries Society, 2007. 178p.

LOPES, P.R.D.; OLIVEIRA-SILVA, J.T.; SENA, M.P. Ocorrência de Rachycentron canadum (Linnaeus, 1766) (Actinopterygii: Rachycentridae) na Baía de Todos os Santos, Estado da Bahia, Brasil. Sitientibus, v.1, p.56-59, 2001.

NEEDHAM, T.; WOOTTEN, R. The parasitology of fishes. In: ROBERTS, R. Fish Pathology. London: Bailliere Tindall, 1978. p.144-185.

NHU, V.C.; NGUYEN, Q.H.; LE, T.L. et al. Cobia Rachycentron canadum aquaculture in Vietnam: recent developments and prospects. Aquaculture, v.315, p.20-25, 2011.

PEREGRINO JR., R.B. Análise do conteúdo estomacal do beijupirá, Rachycentron canadum (Linnaeus, 1766), na costa do Estado de Pernambuco. 2005. 18f. Monografia (Graduação em Engenharia de Pesca). Universidade Federal Rural de Pernambuco, Recife.

SHAFFER, R.V.; NAKAMURA, E.L. Synopsis of biological data on the cobia Rachycentron canadum (Pisces: Rachycentridae). FAO Fisheries Synopsis 153. US Department of Commerce, NOAA Technical Report, 1989. Washington D.C.

SCHWARZ, M.H.; SMITH, S.A. Getting acquainted with Amyloodinium ocellatum. Commercial fish and shellfish technology. Virginia: Virginia Cooperative Extension. Fact Sheet. Publication 600-200. 1998. 2p.

VAN DER VELDE, T.D.; GRIFFITHS, S.P.; FRY, G.C. Reproductive biology of the commercially and recreationally important cobia Rachycentron canadum in northeastern Australia. Fish. Sci., v.76, p.33-43, 2010.

WEIRICH, R.C.; STOKES, A.D.; SMITH, T.I.J. et al. Cobia aquaculture research in South Carolina, USA. In: LIAO, I.C. e LEAÑO, E.M. Cobia Aquaculture: research, development and commercial production. Taiwan: Asian Fisheries Society, 2007. p.19-44. 